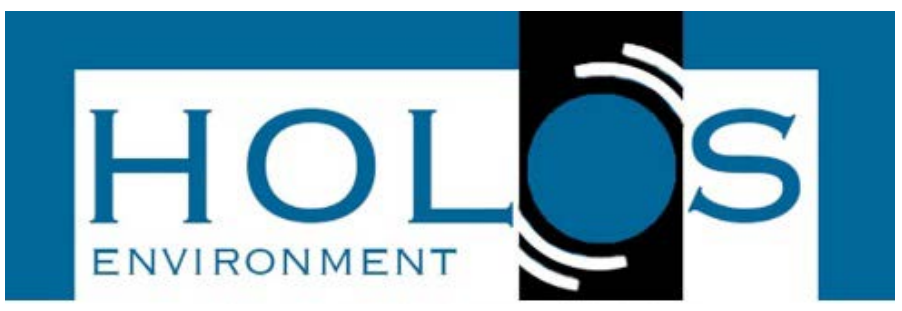

\title{
CARACTERIZAÇÃO E AVALIAÇÃO DA DISTRIBUIÇÃO DE SEDIMENTOS EM SUPERFÍCIES URBANAS
}

\section{CHARACTERIZATION AND EVALUATION OF THE DISTRIBUTION OF SEDIMENTS IN URBAN SURFACES}

\author{
Carolina Mundim de Souza Marques dos Santos ${ }^{1}$, Eduardo Queija de Siqueira ${ }^{1}$, \\ Bernardo Guedes Ariza ${ }^{1}$
}

Artigo recebido em: 01/08/2016 e aceito para publicação em: 29/01/2017.

DOI: http://dx.doi.org/10.14295/holos.v17i1.11646

Resumo: Sedimentos urbanos são potencialmente poluidores devido sua capacidade de associação a poluentes como metais pesados, aumentando a possibilidade de contaminação de corpos d'água em ambiente urbano. Devido à pouca quantidade de estudos relacionados aos sedimentos urbanos, este artigo visa analisar a granulometria, a fração orgânica e inorgânica e quantificar a carga e o acúmulo de sedimentos, verificando sua relação com o fluxo de veículos e a ocorrência de precipitação. Para tal, foram selecionadas três ruas com diferentes fluxos de veículos, onde foram coletados sedimentos nas sarjetas pelo método da escovação e aspiração. Também foram analisados os sedimentos contidos nos filtros de um amostrador de partículas de grande volume localizado em uma das áreas estudadas. Foram realizadas análises granulométricas por difratometria a laser, e a carga e o acúmulo foram determinados por pesagem em balança analítica de precisão e avaliados temporalmente. Os resultados mostram que a carga de sedimentos tem uma relação inversa com a ocorrência/intensidade de precipitação e com o fluxo de veículos. Quanto à fração orgânica e inorgânica, foi possível verificar que a via com maior presença de arborização apresentou maior fração orgânica, e que os sedimentos das vias apresentam, de modo geral, maior fração orgânica que os sedimentos de solo natural. O diâmetro médio das partículas apresentou uma tendência de aumento com a ocorrência de chuvas, e uma relação direta com o fluxo de veículos, onde a via com fluxo maior apresentou as maiores granulometrias.

Palavras-chave: Sedimento urbano. Carga. Acúmulo. Poluição difusa. Granulometria.

Abstract: Urban sediments are potentially polluting because of their capacity to associate with pollutants such as heavy metals, increasing the chance of contamination of water bodies in urban environment. The little amount of studies related to composition of urban sediments, this article aims to analyze the particle size distribution, organic / inorganic fraction and quantify the load and accumulation of sediments collected at each point by checking its relation to vehicle flow and the occurrence of precipitation. To this end, three streets were selected with different flows of vehicles, where sediments were collected in the gutters by brushing and vacuuming method. Also filters of a high volume sampler particles were analyzed. Laser diffraction analyzes were performed to determine the particle size and the load and accumulation were determinaded by weighing in analytical precision balance. The results show that the sediment load has an inverse relationship with the occurrence / intensity precipitation and the traffic flow. It was possible to verify that the street with greater afforestation shows a bigger organic fraction, and the sediments of streets have a bigger organic fraction than "white" sediments. The medium diameter of particles show an increasing trend with occurency of precipitation, and a direct relation with the flow of vehicles, where the route with greater flow of vehicles had the highest grain sizes.

\footnotetext{
${ }^{1}$ Universidade Federal de Goiás (UFGO). Emails: (mundimcarol@gmail.com, eduqs@yahoo.com, bernardo.ariza@gmail.com)
} 
Keywords: Urban sediment. Sediment load. Accumulation. Diffuse pollution. Granulometry.

\section{INTRODUÇÃO}

A geração e contaminação de sedimentos urbanos se agravou com a crescente urbanização, ocorrida nas últimas décadas. Questões referentes à falta de planejamento da expansão urbana em municípios, incluindo infraestrutura de tratamento e destinação adequada de águas pluviais; à ocupação de áreas destinadas à preservação ambiental; à crescente impermeabilização (telhados, vias, calçadas, entre outros); e ao uso intensivo do solo, vêm causando o aumento do escoamento superficial e a redução da taxa de infiltração. Oscilação que provoca o aumento do transporte de sedimentos e poluentes aos cursos d'água (POLETO et al., 2009). Além do escoamento superficial, esses sedimentos urbanos também podem ser carreados pelo vento, podendo prejudicar a saúde humana e dos ecossistemas aquáticos.

Estudos realizados por Charlesworth e Lees (1999, 2003), Sutherland (2003), Al-Khashmanh (2004), Duzgoren-Aydin et al. (2006), Pereira et al. (2007), e Poleto e Castilho (2008), apontam que as maiores fontes de sedimentos urbanos são: construção civil; material proveniente de superfícies das vias; veículos automotores; atividades comerciais e industriais; resíduos sólidos; esgotos; resíduos de vegetação; e deposição atmosférica. Estas fontes são comuns em ambientes urbanos, podem sofrer efeito das condições climáticas, como a intensidade e direção do vento e a dinâmica atmosférica; e de uso e ocupação do solo, como o percentual de áreas impermeáveis, bem como a vocação socioeconômica da região. Há também interferência do fluxo veicular, da existência de sistemas de drenagem, do estado das construções urbanas, da densidade de árvores e vegetação urbana e da ocorrência limpeza das ruas (MARTINEZ, 2010). Dentre os componentes associados aos sedimentos urbanos estão partículas de vidro e metálicas, resíduos de processos industriais e da construção civil, patógenos, nutrientes, matéria orgânica, lixo, detritos, hidrocarbonetos e metais pesados (POLETO e MARTINEZ, 2011; SILVA, 2014).

As Partículas Totais em Suspensão (PTS) são oriundas principalmente de emissões antropogênicas, tais como queimas de resíduos, fuligem, indústrias, combustão de veículos automotores e produção de energia; e são outro fator 
importante relacionado à produção de sedimentos. As PTS são compostas por partículas cujo diâmetro aerodinâmico é menor que $50 \mu \mathrm{m}$. Essas partículas estão entre os poluentes atmosféricos mais comuns, e metais em sua forma sólida estão comumente associados a elas (BRAIT e FILHO, 2010).

A relação granulométrica dos sedimentos afeta a dinâmica de transporte destes no ar, e determina a associação dos sedimentos com poluentes, seu transporte e sua dissolução e reação na água (MARTINEZ, 2010). Além disso, auxilia no desenvolvimento de projetos dos componentes de sistemas de drenagem, pois através dela é possível definir os diâmetros das partículas que se propagarão até o corpo receptor e daquelas que ficarão retidas no sedimentador/decantador (DOTTO, 2006). A análise granulométrica sofre alterações de acordo com a incidência de chuva. Estudando a acumulação de poluentes em uma via urbana de Melbourne (Austrália) Vaze e Chiew (2002) verificaram que apenas uma porção da carga de poluentes é removida por eventos de precipitação. A associação de poluentes em sedimentos de granulometria fina está relacionada à carga elétrica e ao incremento da área superficial nas partículas de menor tamanho, fornecendo maior espaço para a adsorção de metais em argilominerais ou na matéria orgânica presente nas partículas de sedimento (MARTINEZ, 2010).

Visto que a precipitação interfere na qualidade do ambiente lavando a atmosfera e as superfícies onde cai, e sabendo-se que fontes difusas de poluição são as formas mais complexas de serem mensuradas, este estudo visa contribuir para o entendimento da distribuição e composição dos sedimentos em ambiente urbano, no tempo e espaço. Busca-se avaliar a distribuição de sedimentos, relacionando-a com o volume de tráfego e ocorrência de chuvas, e serão comparadas as características granulométricas e a fração orgânica/inorgânica com os solos encontrados em áreas menos antropizadas, aqui denominados como sedimentos de branco.

\section{MATERIAIS E MÉTODOS}

\section{1 Área de estudo}

O município de Goiânia está localizado na região Centro-Oeste do país, possui uma área de 739 km² e uma população estimada em 1.393 .575 habitantes, sendo o 
município mais populoso do estado de Goiás. O clima goianiense é predominantemente tropical, com duas estações bem definidas, a estação chuvosa (predominantemente no período de dezembro a março), e estação seca (predominantemente no período de junho a agosto). De acordo com dados do IBGE (1992) e da Secretaria Municipal de Desenvolvimento Urbano Sustentável - SEMDUS (2002), o período de maior pluviosidade é de dezembro a março com precipitação média mensal acima de $250 \mathrm{~mm}$. O período compreendido entre abril e setembro corresponde à estação seca, período no qual a precipitação média de junho a agosto fica abaixo de 10mm (LUIZ e MESQUITA, 2004). O solo local possui componentes característicos do bioma cerrado, apresentando em sua composição uma fração de areia, seguida por argila e silte. O teor de matéria orgânica presente nesse solo é baixo, ficando geralmente entre 3 e 5\%, devido à rápida decomposição da matéria orgânica pelo sol (COUTINHO, 2000).

Para esta pesquisa foram selecionadas três vias no município de Goiânia com diferentes intensidades de tráfego de veículos, definidas em baixa, média e alta, em diferentes regiões do município. O fluxo de veículo foi determinado pela "Ficha de Contagem Volumétrica I" (BRASIL, 2006, p. 104), do Manual de Estudos de Tráfego. A declividade longitudinal foi determinada pelo programa X-Clinometer em três pontos para cada rua, e foi calculado o valor médio. Para levantamento de dados do uso do solo, como densidade demográfica, uso da via (residencial, industrial, comercial) e presença de áreas impermeáveis, foi realizada uma pesquisa in loco e foram utilizados dados do Anuário Estatístico de 2010, (Secretaria Municipal de Desenvolvimento Urbano Sustentável - SEMDUS, Goiânia). As ruas selecionadas foram denominadas Ponto 1 (rua de baixo fluxo de veículos), Ponto 2 (rua de alto fluxo de veículos), e Ponto 3 (rua de fluxo intermediário de veículos). As imagens das vias podem ser verificadas na Figura 1.A; 1.B e 1.C.

Eventos de chuva foram registrados pelo Instituto Nacional de Meteorologia INMET e nos pontos de coleta, por meio de questionamentos aos moradores da região.

\subsection{Amostragem do sedimento}

As coletas de sedimentos foram realizadas no período de junho a outubro, Holos Environment (2017), 17 (1): 15-34. 18 
durante quatro dias mensais. As coletas tinham por objetivo a determinação da carga, granulometria e fração orgânica/inorgânica dos sedimentos. O período de junho a outubro foi escolhido pelo fato de abranger toda a época de seca e a época de transição para o período chuvoso (outubro). Foram coletados sedimentos em uma área total de $3 \mathrm{~m}^{2}$ na sarjeta de cada via, sendo divididos em 6 parcelas de $0,5 \mathrm{~m}^{2}$ $(0,707 \mathrm{~m} \times 0,707 \mathrm{~m})$ delimitadas por uma moldura de madeira, distantes 5 metros, conforme representado na Figura 1. Procurou-se coletar as amostras sempre no mesmo local. Para obtenção de uma amostra representativa, as subamostras coletadas em cada uma das 6 parcelas foram misturadas e homogeneizadas para composição de apenas uma amostra diária para cada via. As amostras foram coletadas, depositadas em recipientes plásticos e analisadas.

Figura 1 - Vias estudadas: 1.A - Ponto 1; 1.B - Ponto 2; 1.C: Ponto 3; 1.D Alocação das subamostras na via

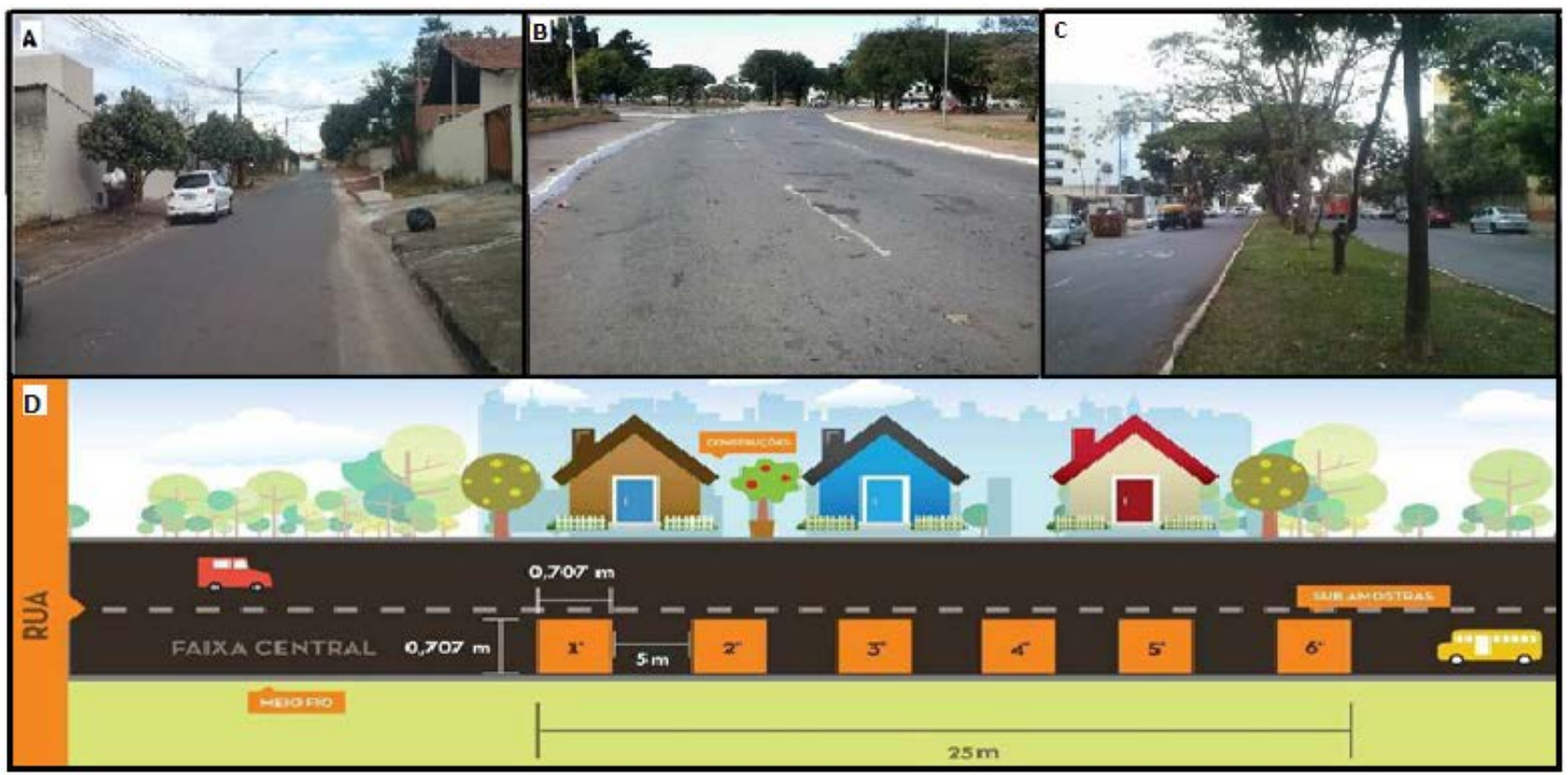

A coleta foi realizada pelo método de escovação e aspiração proposto por Vaze e Chiew (2002), e que consiste em aspirar os sedimentos sobre o asfalto utilizando um aspirador de pó portátil, de potência $12 \mathrm{~V}$, sem peças metálicas e uma escova plástica para escovação da área. Primeiro, a superfície de $0,5 \mathrm{~m}^{2}$ foi aspirada sem escovação, coletando a chamada carga livre. Em seguida, a mesma superfície foi escovada para que então os poluentes finos agregados à superfície fossem soltos, constituindo a carga fixa.

Foram realizadas coletas de amostras de solo local, que foram consideradas 
como amostras de "branco", para a comparação com os sedimentos coletados nos arruamentos. Para o Ponto 1, a coleta do "branco" foi realizada às margens do córrego Vitória, que fica a aproximadamente $1 \mathrm{~km}$ do ponto de coleta. Nos pontos 2 e 3 essas coletas foram realizadas em solo escavado de construções adjacentes aos pontos de coleta. Para a coleta do "branco', o solo foi escavado e foi retirada uma amostra a aproximadamente $10 \mathrm{~cm}$ de profundidade no interior do solo.

Próximo ao Ponto 2 há um Amostrador de Grande Volume para Partículas Totais em Suspensão - AGV PTS, de responsabilidade da Secretaria Estadual de Meio Ambiente e Recursos Hídricos de Goiás - SEMARH. O aparelho coleta amostras a uma altura de $1,85 \mathrm{~m}$ do chão e funciona succionando ar do ambiente que passa através de um filtro, instalado dentro de uma casinhola abrigada, normalmente, por um período de amostragem de 24 horas (DIAS, 2012). Para verificarmos se existe uma relação entre a massa por unidade de volume medida pelo aparelho e a carga por unidade de área medida no solo, foram retiradas amostras mensais de sedimentos contidos no filtro do interior do aparelho. As amostras foram pesadas em uma balança de precisão para a determinação da massa de material particulado, que foi determinada pela diferença do peso do filtro antes de ser utilizado e após a retirada do filtro.

\subsection{Análises das amostras}

As amostras coletadas nas sarjetas das vias foram encaminhadas ao laboratório e submetidas à secagem a $100^{\circ} \mathrm{C} \pm 3^{\circ} \mathrm{C}$ por $24 \mathrm{~h}$ em estufa de secagem para remover a umidade, conforme estudos de Sutherland (2003), e Vaze e Chiew (2002). A determinação da massa dos sedimentos da sarjeta e dos filtros do AVG PTS foi realizada por gravimetria em balança analítica de precisão. Após secagem e pesagem, as amostras individuais de cada dia foram agrupadas e homogeneizadas para obter maior representatividade. As amostras compostas foram analisadas quanto à distribuição granulométrica e determinação de fração orgânica e inorgânica.

A análise granulométrica foi realizada por difratometria a laser e utilizou o método instrumental descrito por Bortoluzzi e Poleto (2006), que consiste em determinar o tamanho das partículas por meio do uso de laser. As amostras foram primeiramente peneiradas em peneiras de nylon, para separação de frações entre 
1000 e $500 \mu \mathrm{m}$ e menores que 500 $\mu \mathrm{m}$. Uma fração das amostras coletadas em cada ponto (aproximadamente $2 \mathrm{~g}$ ), de diâmetro inferior a $500 \mu \mathrm{m}$, foi submetida a prétratamento para eliminação da matéria orgânica, com o uso de agente oxidante, peróxido de hidrogênio $\left(\mathrm{H}_{2} \mathrm{O}_{2}, 30 \%\right)$, e remoção da umidade por secagem durante 24 horas na estufa, a uma temperatura de $105^{\circ} \mathrm{C}$.

Após o tratamento dessa parte das amostras de diâmetro inferior a 500 $\mu \mathrm{m}$, essa foi encaminhada ao aparelho de difração a laser da Malvern, modelo HYDRO 2000MU, com leitura pelo software Mastersize 2000 para obtenção da granulometria das partículas. As análises foram realizadas no Laboratório de Geomorfologia, Pedologia e Geografia Física - LABOGEF do Instituto de Ciências Socioambientais da UFG. A análise consiste em adicionar um percentual da amostra em um Becker preenchido com cerca de $300 \mathrm{~mL}$ de água destilada. Nesse ambiente, o módulo ultrassom e a velocidade de rotação dispersam as partículas e quebram os flocos. Os dados obtidos de distribuição foram tratados no GRADISTAT, um programa estatístico de análise de sedimentos (SILVA, 2014).

Para as análises de sólidos fixos e voláteis foi utilizada a metodologia descrita pelo STANDART METHODS (2540 E), pela qual foram realizadas análises gravimétricas, utilizando-se diluição das amostras secas em água destilada, seguida de secagem a $103^{\circ} \mathrm{C}-105^{\circ} \mathrm{C}$ e ignição da amostra a $550^{\circ} \mathrm{C}$. Essas análises foram realizadas no Laboratório de Saneamento da Escola de Engenharia Civil da UFG.

\section{RESULTADOS E DISCUSSÃO}

\subsection{Caracterização dos pontos amostrais e precipitação durante o período amostral}

A Tabela 1 apresenta as características de cada ponto quanto à densidade demográfica do setor, ao fluxo de veículos da via, e à classificação, declividade e característica da via. A Tabela 2 apresenta o total precipitado em cada mês estudado. 
Tabela 1 - Características de cada ponto

\begin{tabular}{|c|c|c|c|}
\hline & $\begin{array}{c}\text { Ponto } 1 \text { - Jardim } \\
\text { Mariliza }\end{array}$ & $\begin{array}{c}\text { Ponto } 2 \text { - Setor } \\
\text { Central }\end{array}$ & $\begin{array}{c}\text { Ponto } 3 \text { - Setor } \\
\text { Universitário }\end{array}$ \\
\hline $\begin{array}{c}\text { Densidade } \\
\text { Demográfica }\end{array}$ & $4736 \mathrm{hab} / \mathrm{km}^{2}$ & 6955 hab $/ \mathrm{km}^{2}$ & 6411 hab $/ \mathrm{km}^{2}$ \\
\hline $\begin{array}{l}\text { Fluxo de Veículos e } \\
\text { Classificação } \\
\text { Declividade }\end{array}$ & 100 (Baixo) & 14.241 (Alto) & 5.000 (Intermediário) \\
\hline Longitudinal & $\begin{array}{c}1 \% \\
\text { - Uso residencial; }\end{array}$ & $1 \%$ & $3 \%$ \\
\hline Característica da Via & $\begin{array}{l}\text { - Superfície asfáltica } \\
\text { parcialmente } \\
\text { conservada; } \\
\text { - Presença de algumas } \\
\text { árvores; } \\
\text { - Apenas algumas } \\
\text { calçadas } \\
\text { impermeabilizadas; }\end{array}$ & $\begin{array}{l}\text { - Uso comercial e } \\
\text { residencial; } \\
\text { - Superfície asfáltica } \\
\text { desgastada; } \\
\text { - Presença de algumas } \\
\text { árvores no canteiro } \\
\text { central; } \\
\text { - Calçadas } \\
\text { impermeabilizadas; }\end{array}$ & $\begin{array}{l}\text { - Uso comercial e } \\
\text { residencial; } \\
\text { - Superfície asfáltica } \\
\text { desgastada; } \\
\text { - Presença de muitas } \\
\text { árvores; } \\
\text { - Calçadas } \\
\text { impermeabilizadas }\end{array}$ \\
\hline
\end{tabular}

Tabela 2 - Precipitação mensal total no período experimental

\begin{tabular}{cccccc}
\hline & Junho & Julho & Agosto & Setembro & Outubro \\
Precipitação & 0 & 15,7 & 0 & 31,3 & 69,2 \\
mensal $(\mathrm{mm})$ & & & & & \\
\hline Fonte: Inmet (2014) & & & & &
\end{tabular}

\subsection{Carga e acúmulo}

A carga total coletada por mês em cada via está representada na Tabela 3. A Figura 2 demonstra as cargas totais, divididas em suas frações livre e fixa.

Tabela 3 - Cargas totais por mês em cada ponto estudado, em $\mathrm{g} / \mathrm{m}^{2}$

\begin{tabular}{ccccccc}
\hline Ponto & Junho & Julho & Agosto & Setembro & Outubro & TOTAL \\
\hline 1 & 95,75 & 86,00 & 143,16 & 91,52 & 66,19 & 482,62 \\
2 & 101,34 & 79,25 & 63,91 & 98,44 & 92,19 & 435,13 \\
3 & 81,03 & 66,13 & 81,53 & 43,90 & 65,24 & 337,84 \\
TOTAL & 278,12 & 231,38 & 288,60 & 233,87 & 223,62 & \\
\hline
\end{tabular}


Figura 2 - Cargas totais divididas em carga livre e fixa

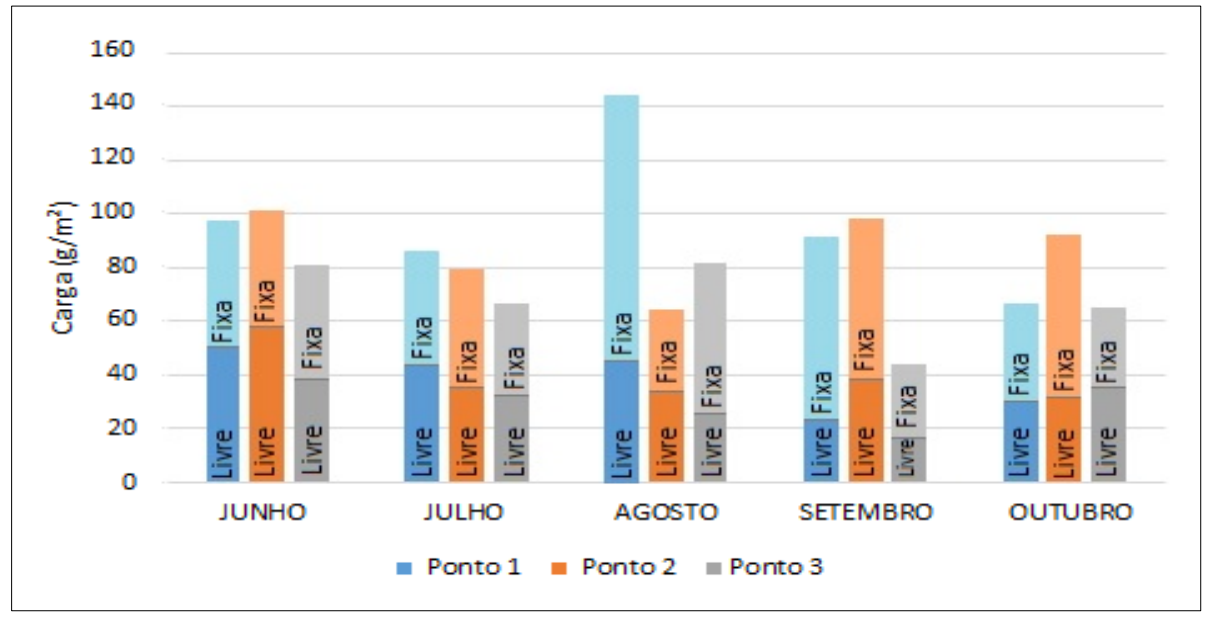

A via de baixo fluxo de veículos (Ponto 1) apresentou a maior carga de sedimentos, sendo o valor da carga acumulada em todos os meses de $482,62 \mathrm{~g} / \mathrm{m}^{2}$, e sua variação de $143,16 \mathrm{~g} / \mathrm{m}^{2}$ em agosto a $66,19 \mathrm{~g} / \mathrm{m}^{2}$ em outubro. Podemos observar que a carga de $143,16 \mathrm{~g} / \mathrm{m}^{2}$ foi a maior carga mensal de sedimentos e ocorreu no mês de agosto, onde não foram registrados eventos de precipitação. O Ponto 2 , de alto fluxo de veículos, foi o segundo a ter maior carga total, de $435,13 \mathrm{~g} / \mathrm{m}^{2}$, com sua carga variando entre $63,91 \mathrm{~g} / \mathrm{m}^{2}$ a $101,34 \mathrm{~g} / \mathrm{m}^{2}$, e o Ponto 3 teve a carga de $337,84 \mathrm{~g} / \mathrm{m}^{2}$ acumulada durante os meses, com variação entre $43,90 \mathrm{~g} / \mathrm{m}^{2}$ a $81,03 \mathrm{~g} / \mathrm{m}^{2}$. Atribui-se as cargas baixas ocorridas no Ponto 3 à maior declividade longitudinal em relação às demais vias, de $3 \%$. Pode-se observar que as cargas variam bastante de um local para outro e podem ser influenciadas por fatores como declividade, uso do solo e tráfego de veículos.

Os meses que apresentaram maior carga total foram os meses de junho e agosto (Tabela 3), em que não houve registros de precipitações, seguido dos meses de julho, outubro e setembro, em que foram registrados eventos de precipitações.

Com relação à carga livre e carga fixa, pode-se verificar que nos meses onde houve o prevalecimento da carga fixa houve também registros de precipitação, o que pressupõe que o percentual de carga livre e fixa está relacionado à ocorrência de precipitação. Isso provavelmente ocorre devido ao fato da carga fixa estar parcialmente agregada à superfície de asfalto, enquanto a carga livre pode ser facilmente redistribuída por vento, precipitação, varrição, tráfego e outros fatores. $\mathrm{Na}$ ocorrência de precipitações, a parte da carga que não é dissolvida e nem carreada se 
torna parte da carga fixa, uma vez que se liga à superfície após a secagem.

Dotto (2006), e Vaze e Chiew (2002) realizaram estudos sobre a acumulação de sedimentos em vias urbanas utilizando a mesma metodologia de coleta deste trabalho, e relacionaram o acúmulo de carga livre e fixa com eventos de precipitação. Observou-se que a carga total é diminuída após a maioria dos eventos de precipitação, independentemente da intensidade desta, e que há aumento do percentual da carga fixa após eventos de precipitação de pouca intensidade. Em eventos de precipitação de grande intensidade, eles observaram a diminuição da carga livre e fixa, devido ao carreamento pelo escoamento.

A Figura 3 representa as cargas totais (livre e fixa somadas para cada via) e os eventos de precipitação que ocorreram, com seus respectivos volumes. O acúmulo das partículas pode ser verificado de forma mais evidente entre os períodos de 26 de junho a 30 de agosto, em que há um acréscimo gradativo das cargas no tempo. Mesmo em curtos períodos, como entre os eventos de precipitações dos dias 8 de setembro e 16 de setembro, e 14 de outubro e 16 de outubro, fica evidente o processo de acumulação.

Analisando o efeito das precipitações sobre as cargas, pode-se perceber, de forma geral, que os eventos de precipitação diminuíram a carga em todos os pontos. Pode-se justificar essa diminuição devido ao fato da precipitação cair sobre a superfície do asfalto e deslocar as partículas presentes. A única exceção foi o Ponto 2, que teve sua carga aumentada após os eventos de precipitação anteriores à data de 8 de setembro. Esses eventos foram de baixa intensidade e com datas distantes entre si. Pode-se justificar esse aumento da carga pelo fato de que pequenos eventos de precipitação proporcionam a mobilidade das partículas mais finas da carga, em que uma parte é carreada pelo escoamento e a outra é redistribuída sobre a superfície. O alto fluxo de veículos e a ocorrência de precipitações de baixa intensidade, que possuem uma capacidade menor de carreamento, facilitam a redistribuição. Assim as partículas são deslocadas para pontos mais baixos da via e se acumulam.

Com relação à quantidade de carga diária, pode-se verificar a variação de cargas de $11,3 \mathrm{~g} / \mathrm{m}^{2}$ a $40,0 \mathrm{~g} / \mathrm{m}^{2}$. Estes valores ocorreram, no Ponto 3, no dia 8 de setembro, e no Ponto 1, no dia 18 de agosto, respectivamente. O Ponto 3 apresenta fluxo intermediário de veículos, mas grande declividade em comparação aos outros pontos, o que justifica a menor carga. Silva (2013), em estudo de mesma natureza no 
município de Goiânia, encontrou, em uma parcela de mesma área, cargas que variaram de 0,5 a $99,2 \mathrm{~g} / \mathrm{m}^{2}$. Sendo a carga de $99,2 \mathrm{~g} / \mathrm{m}^{2}$ encontrada na rua de baixo fluxo de veículos e a carga de $0,5 \mathrm{~g} / \mathrm{m}^{2}$ encontrada na via de alto fluxo de veículos, o que sugere haver uma correlação negativa entre o fluxo e as cargas. Vaze e Chiew (2002), na Austrália, realizaram coletas na faixa central de uma via, onde encontraram cargas entre 5,0 a 55,0g/m². Herngren et al. (2006) encontraram uma variação de 0,8 a 5,3g/m² para vias com diferentes usos do solo em Queensland State, Austrália. Dotto (2006), em Santa Maria, Brasil, encontrou em ruas residenciais uma variação de 4,0 a $350,0 \mathrm{~g} / \mathrm{m}^{2}$.

Figura 3 - Cargas diárias $\left(\mathrm{g} / \mathrm{m}^{2}\right)$ de sedimentos e volume precipitado $(\mathrm{mm})$

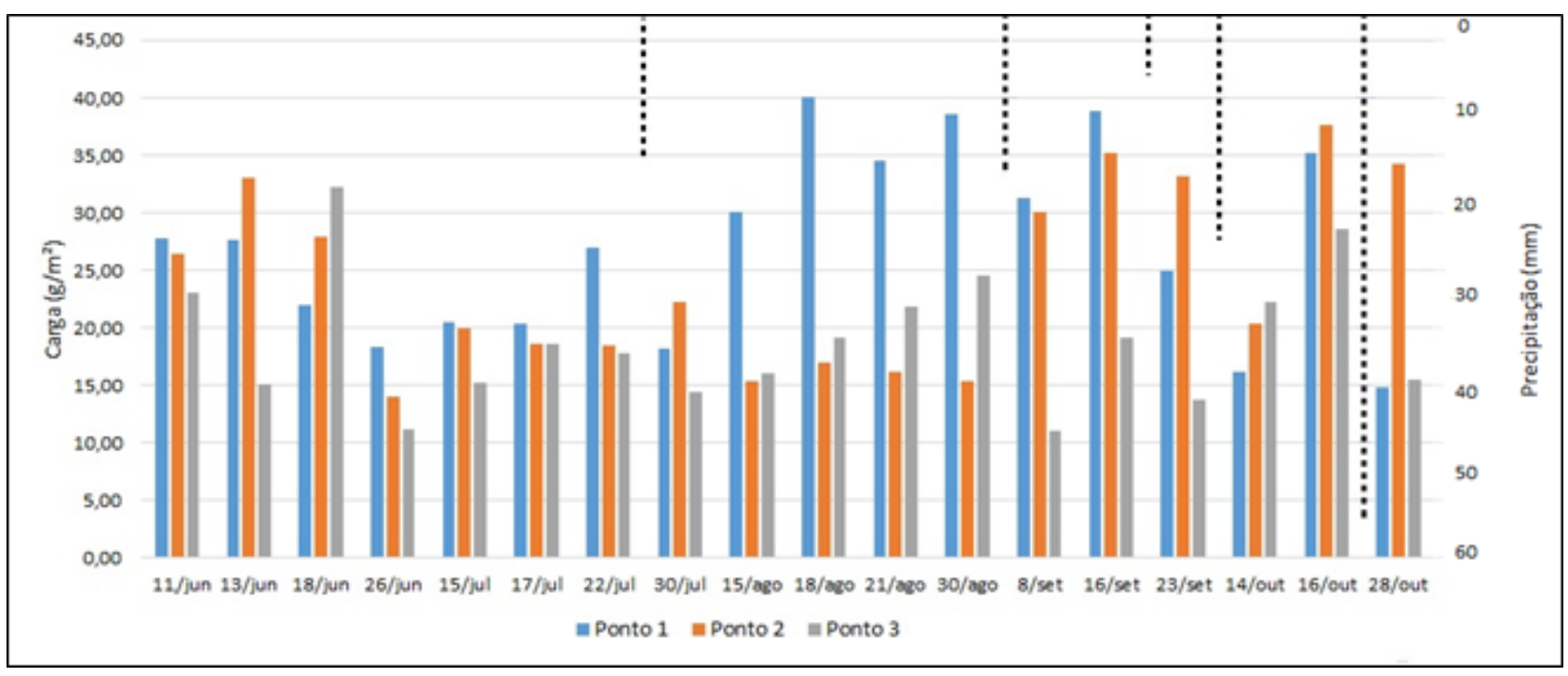

A Figura 4 representa os acúmulos lineares nos períodos citados. O acúmulo variou de 0,00 a 9,55g/m² dia e teve uma tendência de crescimento de junho para outubro. Isso provavelmente se deve ao depósito de partículas suspensas no ar na superfície do asfalto. Egodawatta e Goonetilleke (2007) constataram que o acúmulo de poluentes é rápido nos primeiros dias após eventos de precipitação, mas tende ao equilíbrio entre o sétimo e nono dia. 
Figura 4 - Representação do acúmulo das cargas, por período

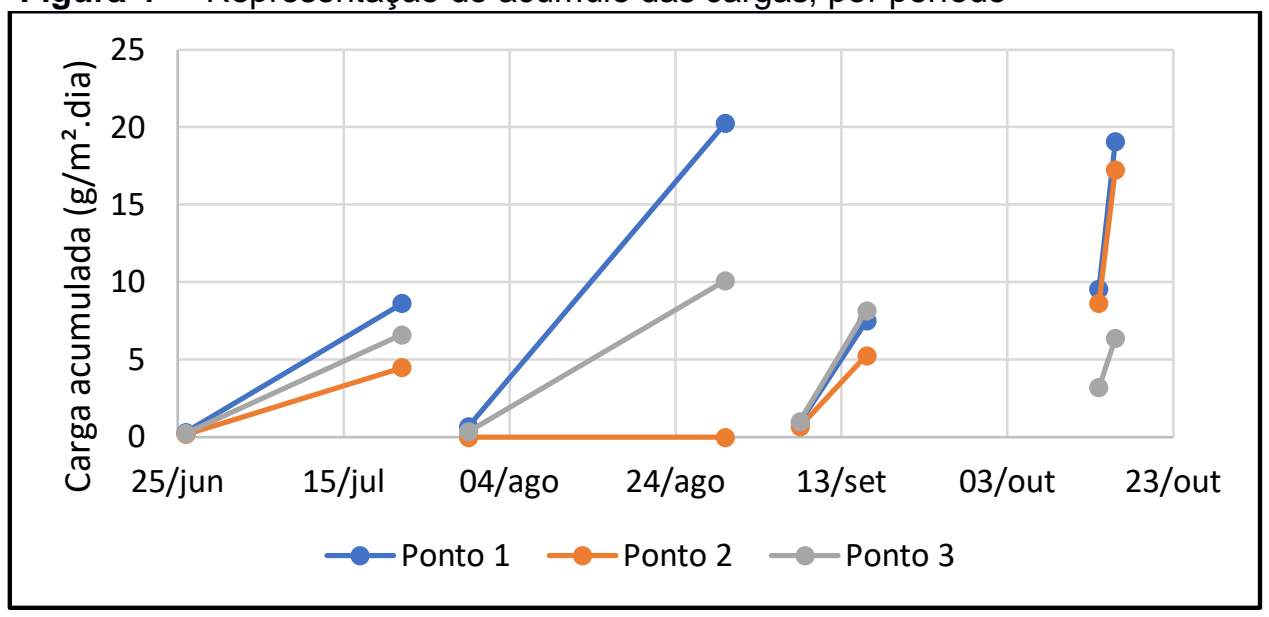

A massa de material particulado atmosférico, denominado como PTS (Partículas Totais em Suspensão), medida com o amostrador de partículas de grande volume - AVG PTS, foi calculada pela equação fornecida pelo Manual de Operação AVG PTS (2006), que relaciona a massa de particulado $(\mu \mathrm{g})$ com o volume total amostrado $\left(\mathrm{m}^{3}\right)$.

Nicodemos et. al (2008) em seu estudo sobre qualidade do ar, realizado no município de Uberlândia, elaborou uma tabela com base no Índice de Qualidade do Ar utilizado pela CETESB (Companhia de Tecnologia de Saneamento Ambiental) para PTS. Essa tabela classifica o ar como BOM, em que a quantidade de PTS deve estar entre 0 e $80 \mu \mathrm{g} / \mathrm{m}^{3}$ de ar, que é medido no amostrador de partículas; REGULAR, entre 80 e $240 \mu \mathrm{g} / \mathrm{m}^{3}$; INADEQUADA, entre 240 e $375 \mu \mathrm{g} / \mathrm{m}^{3}$; MÁ, entre 375 e $625 \mu \mathrm{g} / \mathrm{m}^{3}$; e PÉSSIMA, onde a quantidade de PTS é maior que $625 \mu \mathrm{g} / \mathrm{m}^{3}$. A Tabela 4 apresenta os padrões de qualidade do ar estabelecidos pela CETESB e as quantidades de PTS encontradas no amostrador de partículas do presente estudo.

Tabela 4 - Padrões de qualidade e quantidade de PTS encontradas no amostrador

Quantidade de PTS encontrado nos filtros $\left(\mu \mathrm{g} / \mathrm{m}^{3}\right)$

\begin{tabular}{ccccc}
\hline Classificação da Qualidade do & PTS $\left(\boldsymbol{\mu g} / \mathbf{m}^{3}\right)$ & Agosto & Setembro & Outubro \\
Ar & $0-80$ & & & 74,03 \\
Bom & $80-240$ & & 149,79 & \\
Regular & $240-375$ & & & \\
Inadequada & $375-625$ & 454,51 & & \\
Má & $>625$ & & & \\
Péssima & & & \\
\hline
\end{tabular}


Ao se analisar a Tabela 4 podemos verificar que com o passar dos meses a quantidade de PTS tendeu a diminuir, passando da classificação de MÁ, em agosto, para REGULAR, em setembro, e para BOM, em outubro. Isso pode ser justificado pelo início do período de chuvas, que remove as partículas em suspensão e as leva para o solo e superfícies.

A Figura 5 apresenta a relação entre a carga de sedimentos encontrados na sarjeta e a concentração medida com o amostrador de partículas de grande volume AVG PTS. Os sedimentos da sarjeta tiveram a tendência de aumentar com o início das precipitações, enquanto os sedimentos atmosféricos tiveram a tendência de diminuir. O índice de correlação de 0,8 é considerado como forte por diversos autores como Cohen (1988), Dancey e Reidy (2006). E, por este motivo, a equação de regressão apresentada pode ser utilizada como indicador para estimar valores de concentração tanto da sarjeta quanto do filtro, quando for realizada medição de concentração em um desses locais.

Figura 5 - Correlação entre a carga presente no filtro - AVG PTS e na sarjeta

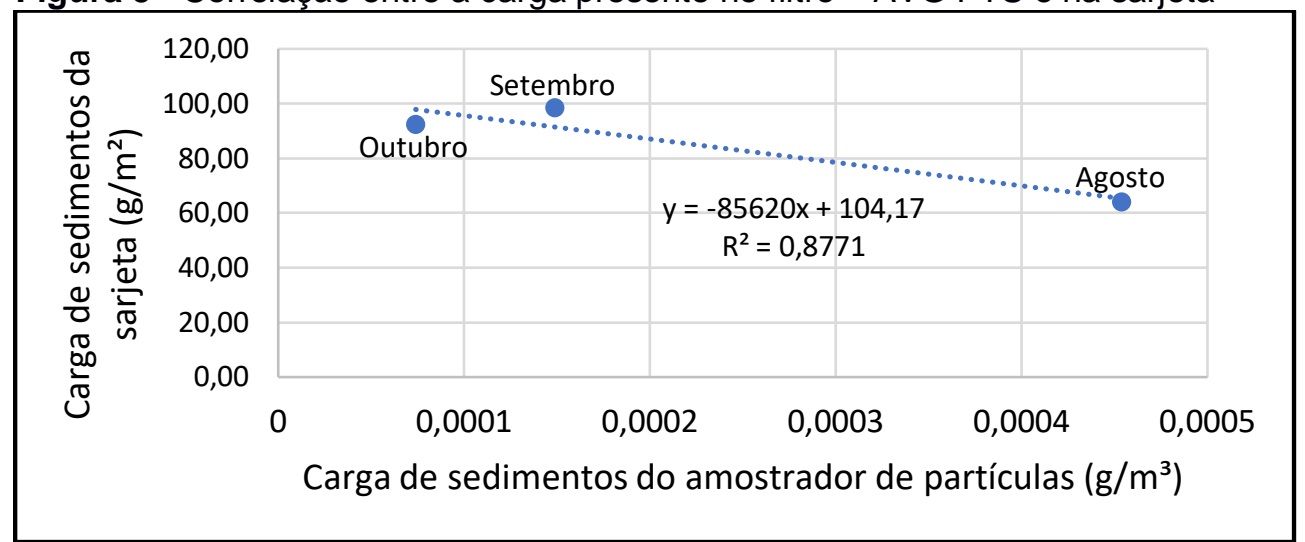

\subsection{Granulometria}

Os sedimentos da sarjeta foram peneirados em peneiras de 1000 e $500 \mu \mathrm{m}$, e pôde-se perceber que as partículas menores que $500 \mu \mathrm{m}$ representaram maior porcentagem em todos os pontos e em todos os meses. Uma fração dos sedimentos de granulometria inferior a $500 \mu \mathrm{m}$, e da amostra de "branco" de cada ponto, foi submetida à análise pelo aparelho de difração a laser da Malvern, modelo HYDRO 2000MU. Pode-se verificar na Figura 6 que os sedimentos encontrados na sarjeta são predominantemente constituídos de areia, em média 70\%, 30\% de silte e $2 \%$ de argila. Houve uma tendência de aumento da granulometria das partículas com o passar dos 
meses. Isto se deve à ocorrência de precipitação, que transporta as partículas menores mais facilmente. Os sedimentos do "branco" apresentaram maior proporção de silte em todos os pontos em relação aos sedimentos coletados na sarjeta, tendo uma média de 60\% areia, 40\% silte e 4\% argila.

Com relação ao fluxo de veículos, pode-se verificar que o Ponto 2, que é o ponto de maior fluxo, apresentou maior granulometria em todos os meses estudados, com uma média de $85 \%$ de areia, 15\% silte e 1\% argila. O Ponto 1, de menor fluxo de veículos, apresentou granulometria menor, sendo a média de 65\% areia, 35\% silte e $2 \%$ argila. Com relação à ocorrência de chuvas, podemos verificar uma tendência de aumento da granulometria das partículas com o aumento das precipitações, sendo que houve precipitações nos meses de julho, setembro e outubro.

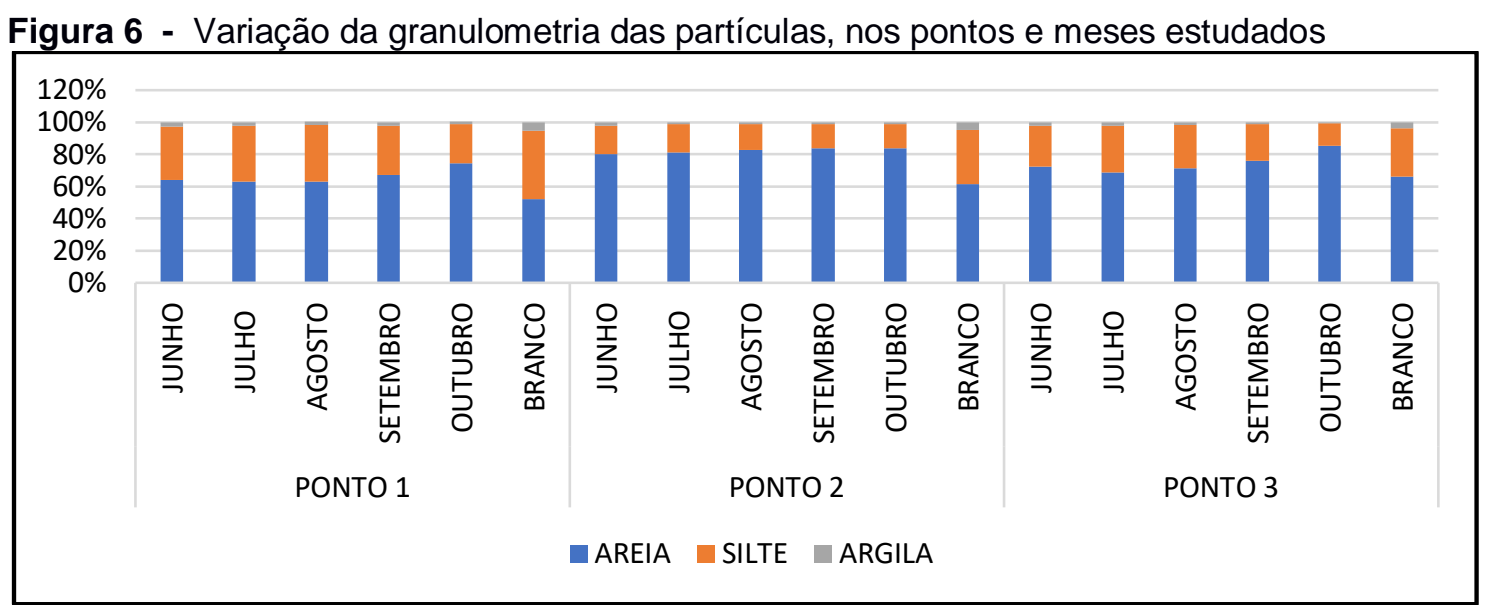

A Tabela 5 apresenta todas as porcentagens das granulometrias coletadas, com divisões de porcentagens de areia muito grossa, grossa, mediana, fina, muito fina, silte grosso, médio, fino, muito fino, e argila, com suas respectivas granulometrias. Analisando a Tabela 5, podemos observar que, dentre as areias, prevaleceram as areias finas e muito finas, de granulometria entre $63 \mu \mathrm{m}$ e $250 \mu \mathrm{m}$, e, dentre os siltes, prevaleceu o silte grosso, de granulometria entre $63 \mu \mathrm{m}$ a $15,6 \mu \mathrm{m}$, de acordo com a escala de Mudroch e Azcue (1995). 
Tabela 5 - Tabela granulométrica com a porcentagem encontrados, segundo classificação de Mudroch e Azcue (1995)

\begin{tabular}{|c|c|c|c|c|c|c|c|c|c|c|c|c|c|c|c|c|c|c|c|}
\hline & & \multicolumn{5}{|c|}{ Ponto 1} & \multicolumn{5}{|c|}{ Ponto 2} & \multicolumn{5}{|c|}{ Ponto 3} & \multicolumn{3}{|c|}{ Brancos } \\
\hline & & mês 6 & mês 7 & mês 8 & mês 9 & mês 10 & mês 6 & mês 7 & mês 8 & mês 9 & mês 10 & mês 6 & mês 7 & mês 8 & mês 9 & mês 10 & Pto.1 & Pto.2 & Pto. 3 \\
\hline & & $\begin{array}{c}\text { Volume } \\
(\%)\end{array}$ & $\begin{array}{c}\text { Volume } \\
(\%)\end{array}$ & $\begin{array}{l}\text { Volum } \\
\text { e (\%) }\end{array}$ & $\begin{array}{c}\text { Volume } \\
(\%)\end{array}$ & $\begin{array}{c}\text { Volume } \\
(\%)\end{array}$ & $\begin{array}{c}\text { Volume } \\
(\%)\end{array}$ & $\begin{array}{c}\text { Volume } \\
(\%)\end{array}$ & $\begin{array}{c}\text { Volume } \\
(\%)\end{array}$ & $\begin{array}{c}\text { Volume } \\
(\%)\end{array}$ & $\begin{array}{c}\text { Volume } \\
(\%)\end{array}$ & $\begin{array}{c}\text { Volume } \\
(\%)\end{array}$ & $\begin{array}{c}\text { Volume } \\
(\%)\end{array}$ & $\begin{array}{c}\text { Volume } \\
(\%)\end{array}$ & $\begin{array}{c}\text { Volume } \\
(\%)\end{array}$ & $\begin{array}{c}\text { Volume } \\
(\%)\end{array}$ & $\begin{array}{c}\text { Volume } \\
(\%)\end{array}$ & $\begin{array}{c}\text { Volume } \\
(\%)\end{array}$ & $\begin{array}{c}\text { Volume } \\
(\%)\end{array}$ \\
\hline AREIA & $\begin{array}{c}2-0,063 \\
\mathrm{~mm}\end{array}$ & & & & & & & & & & & & & & & & & & \\
\hline Muito grossa & $2-1$ & 0,02 & 0,00 & 0,00 & 0,00 & 0,00 & 0,00 & 0,56 & 0,00 & 0,00 & 0,00 & 0,31 & 0,33 & 0,00 & 0,00 & 0,94 & 0,00 & 0,00 & 0,00 \\
\hline Grossa & $1-0,5$ & 2,83 & 2,18 & 0,73 & 2,10 & 3,39 & 4,88 & 8,80 & 3,76 & 4,18 & 3,95 & 9,02 & 4,96 & 0,62 & 1,97 & 16,63 & 3,04 & 3,36 & 8,55 \\
\hline Mediana & $0,5-0,25$ & 13,97 & 13,36 & 8,82 & 14,32 & 17,34 & 21,68 & 19,85 & 23,23 & 27,29 & 30,03 & 23,44 & 13,43 & 9,73 & 12,11 & 28,10 & 14,46 & 27,22 & 29,78 \\
\hline Fina & $\begin{array}{c}0,25-0 \\
125\end{array}$ & 23,23 & 23,37 & 23,54 & 26,51 & 29,85 & 31,39 & 30,77 & 34,58 & 33,77 & 34,83 & 22,53 & 24,35 & 28,35 & 30,41 & 24,68 & 20,99 & 25,25 & 20,75 \\
\hline Muito fina & $\begin{array}{c}0,125- \\
0,063\end{array}$ & 25,63 & 25,53 & 30,76 & 25,72 & 25,00 & 23,09 & 22,13 & 21,84 & 19,26 & 15,81 & 17,87 & 26,74 & 33,34 & 32,44 & 15,58 & 16,42 & 8,21 & 9,19 \\
\hline Total Areia & & 65,67 & 63,24 & 62,89 & 68,13 & 75,46 & 75,04 & 81,43 & 82,73 & 83,86 & 83,98 & 72,13 & 68,73 & 71,24 & 76,25 & 85,49 & 52,27 & 61,56 & 66,31 \\
\hline SILTE & $\begin{array}{c}0,063- \\
0,002 \mathrm{~mm}\end{array}$ & & & & & & & & & & & & & & & & & & \\
\hline Grosso & $\begin{array}{l}0,063- \\
0,0156\end{array}$ & 23,59 & 24,10 & 25,50 & 20,94 & 15,86 & 6,73 & 11,54 & 10,15 & 9,61 & 9,18 & 18,20 & 21,65 & 20,65 & 16,54 & 9,16 & 22,91 & 19,27 & 16,82 \\
\hline Médio & $\begin{array}{c}0,0156- \\
0,0078\end{array}$ & 4,64 & 5,10 & 4,73 & 4,44 & 3,47 & 5,04 & 2,89 & 2,96 & 2,27 & 2,81 & 3,82 & 3,86 & 3,40 & 3,12 & 2,32 & 9,97 & 7,45 & 6,25 \\
\hline Fino & $\begin{array}{c}0,0078- \\
0,0039\end{array}$ & 3,61 & 3,81 & 3,52 & 3,64 & 3,16 & 4,01 & 2,04 & 2,09 & 2,15 & 2,03 & 2,84 & 2,77 & 2,32 & 2,05 & 1,58 & 7,14 & 5,39 & 4,99 \\
\hline Muito Fino & $\begin{array}{c}0,0039- \\
0,002\end{array}$ & 2,50 & 2,52 & 2,41 & 2,35 & 1,97 & 3,17 & 1,41 & 1,43 & 1,44 & 1,38 & 1,96 & 1,90 & 1,56 & 1,37 & 1,05 & 5,11 & 3,86 & 3,67 \\
\hline Total Silte & & 34,33 & 34,33 & 35,20 & 30,85 & 24,34 & 12,95 & 17,20 & 15,95 & 14,83 & 14,76 & 25,78 & 29,10 & 27,13 & 22,40 & 13,67 & 42,49 & 33,49 & 29,77 \\
\hline ARGILA & $\begin{array}{c}<0,002 \\
\mathrm{~mm}\end{array}$ & 2,51 & 2,40 & 2,29 & 2,03 & 1,55 & 2,04 & 1,38 & 1,33 & 1,32 & 1,28 & 2,08 & 2,13 & 1,64 & 1,36 & 0,83 & 5,12 & 4,86 & 3,81 \\
\hline TOTAL & & 100 & 100 & 100 & 100 & 100 & 100 & 100 & 100 & 100 & 100 & 100 & 100 & 100 & 100 & 100 & 100 & 100 & 100 \\
\hline
\end{tabular}

Esse mesmo fato foi constatado por Silva et al. (2015), em análise da distribuição da granulometria de sedimentos urbanos no município de Goiânia, na qual foi constatado que mais de $41 \%$ das frações estavam entre 63 e $250 \mu \mathrm{m}$. Poleto et al. (2009) avaliaram sedimentos de 20 municípios do estado do Rio Grande do Sul, sul do Brasil, em ruas, avenidas e bocas de lobo, e também constataram o prevalecimento dessa mesma faixa granulométrica para os sedimentos. Os autores concluíram que a distribuição granulométrica dos sedimentos encontrados nas ruas e avenidas possui pico na fração menor que $100 \mu \mathrm{m}$, correspondente à areia muito fina, enquanto os sedimentos encontrados em bocas de lobo prevaleceram com granulometria 250$300 \mu \mathrm{m}$ (areia mediana).

\subsection{Fração orgânica e inorgânica}

Na Figura 7 estão apresentados os resultados do ensaio de sólidos fixos e 
voláteis, que representam, respectivamente, a fração inorgânica e orgânica que compõe os sedimentos. Constata-se que a fração inorgânica é superior à fração orgânica, estando as frações em torno de 80\% para inorgânico e 20\% para orgânico. As amostras de "branco" de todos os pontos demonstraram uma fração inorgânica maior que a fração de sedimentos da sarjeta, em torno de 5\% orgânico e 95\% inorgânico, o que é característico do solo do cerrado. A fração orgânica foi mais significativa no Ponto 3, devido ao fato dessa via apresentar um maior número de árvores, que contribui com a incorporação de matéria orgânica ao sedimento pela grande quantidade de galhos e folhas na via.

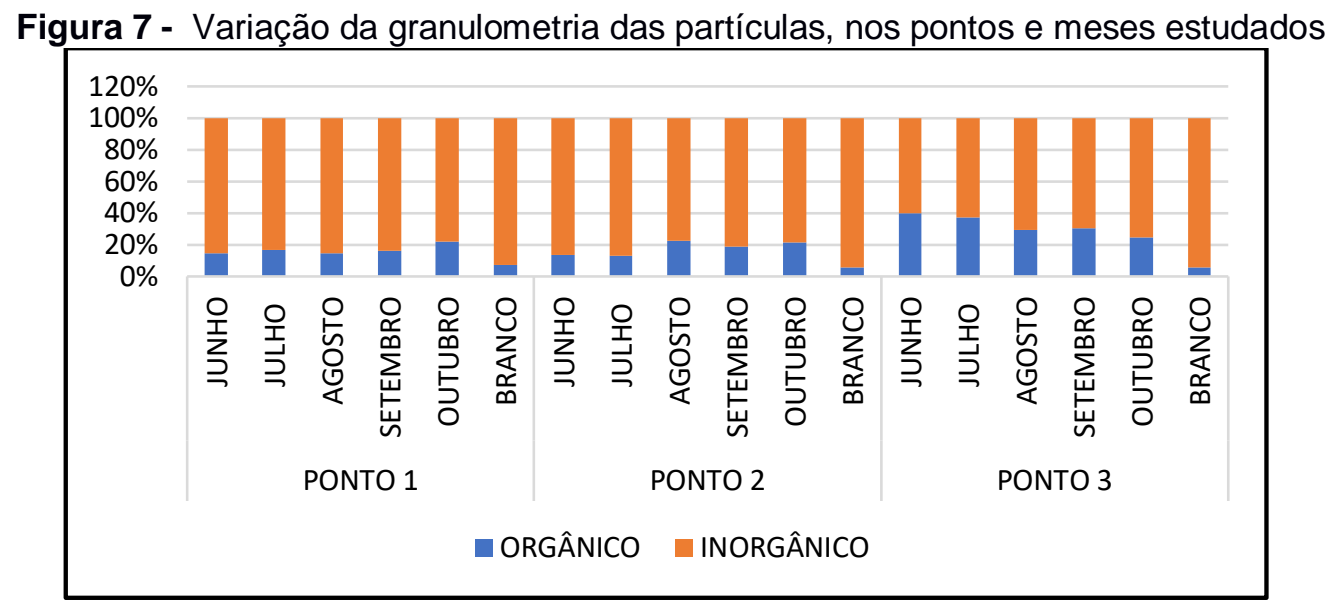

Dotto (2006) utilizou a mesma metodologia deste trabalho para a coleta de sedimentos em vias urbanas, e verificou a presença de materiais como lixo, fibras e vegetação representando em média de $3 \%$ da composição dos sedimentos coletados. As coletas realizadas em vias arborizadas, ou perto de vegetação, representaram uma média de $12 \%$ da composição dos sedimentos, o que também foi constatado nesta pesquisa. Os valores encontrados por Butler \& Clark (1995) em Lambeth, na Inglaterra, também foram compatíveis com os encontrados por Dotto (2006), sendo estes 2\% de matéria orgânica para áreas menos arborizadas e 10\% em áreas mais arborizadas. Silva et al. (2014) encontraram, no município de Goiânia, 20,9\% de massa de matéria orgânica em área urbana arborizada, e uma média de 6,5\% em área menos arborizada. 


\section{CONCLUSÕES}

Os resultados mostram que a carga de sedimentos acumulada nas ruas apresentou uma relação inversa com a intensidade do fluxo de veículos, visto que a carga no Ponto 1, de baixo fluxo de veículos, apresentou as maiores cargas. Também se observou que a carga total diminuiu em meses que houve maior ocorrência de precipitação, sendo que o percentual de carga livre nesses meses tendeu a diminuir e o da carga fixa a aumentar. Fatores como declividade parecem influenciar a carga acumulada, visto que a via com maior declividade apresentou menor carga. O uso do solo também se mostrou um fator importante na composição dos sedimentos, uma vez que características como fluxo de veículos, urbanização e densidade de árvores influenciaram na massa acumulada.

A carga de PTS acumulada no filtro do amostrador de partículas tendeu a diminuir com o passar dos meses devido aos eventos de chuva. Comparando a carga do filtro com a carga presente na sarjeta do Ponto 2, podemos verificar que os sedimentos apresentaram comportamentos contrários. Sendo que os sedimentos da sarjeta tiveram a tendência de aumentar com o início das precipitações, enquanto os sedimentos do filtro tiveram a tendência de diminuir. Isso pode ser justificado pelo fato de o amostrador de partículas coletar material particulado do ar, que apresenta melhora em sua qualidade com o início das precipitações.

Da granulometria dos sedimentos observados pelo ensaio de peneiramento, observou-se que o ponto de fluxo intermediário de veículos, mas que possui grande número de árvores, contém as partículas mais grosseiras, onde cerca de $20 \%$ das frações foram $>1000 \mu \mathrm{m}$. Fato que está diretamente relacionado com o aporte de folhas e gravetos ao sedimento. Nas demais ruas, a faixa de partículas grosseiras foi próxima a $10 \%$ das frações, onde foi possível observar que as partículas grosseiras tendem a diminuir com o aumento do fluxo de veículos. As frações predominantes para todos os pontos foram as < 500 $\mu$ m com mais de $50 \%$. Dessa fração $<500 \mu m$ analisada, pôde-se verificar que a areia representou $80 \%$ dos sedimentos encontrados na sarjeta. A fração inorgânica foi superior à fração orgânica, estando em torno de 80\% inorgânico e 20\% orgânico. As amostras do "branco" demonstraram uma fração inorgânica maior que a fração inorgânica dos sedimentos da sarjeta, estando em torno de 5\% orgânico e 95\% inorgânico, o que é característico do solo do cerrado. 


\section{AGRADECIMENTOS}

Agradecemos à FAPEG pelo incentivo e à SEMARH por disponibilizar o uso de materiais. Aos laboratórios de Saneamento da UFG e ao LABOGEF-IESA da UFG, na pessoa do professor Dr. Maximiliano Bayer.

\section{REFERÊNCIAS}

AL-KHASHMAN, O. Heavy metal distribution in dust, street dust and soils from the work place in Karak Industrial Estate, Jordan. Atmospheric Environment, n. 38, p. $6803-6812$, 2004.

BORTOLUZZI, E. C.; POLETO, C. Metodologias para estudos de sedimentos: ênfase na proporção e a natureza mineralógica das partículas. In: POLETO, C; MERTEN, G. (Org.) Qualidade dos sedimentos. Porto Alegre: ed. ABRH, p. 83-140, 2006.

BRAIT, C. H. H.; FILHO, N. R. A. Desenvolvimento e aplicação de sistema passivo de coleta de poluentes atmosféricos para monitoramento de $\mathrm{Cd}, \mathrm{Cr}, \mathrm{Pb}, \mathrm{Cu}, \mathrm{Fe}, \mathrm{Mn}, \mathrm{Zn}$ e particulados totais. Química Nova, v. 33, n. 1, p. 7-13. 2010.

BRASIL. Departamento Nacional de Infraestrutura de Transportes - Denit. Manual de estudos de tráfego. - Rio de Janeiro, 2006. 384 p. (IPR. Publ., 723). Disponível em: $<$ http://dnit.gov.br/arquivos internet/ipr/ipr new/manuais/manual estudos trafego.pdf>. Acesso em: dez. 2013.

BUTLER, D.; CLARK, P. Sediment management in urban drainage catchments. Construction Research and Information Association (CIRIA). Report 134. London, 1995.

CHARLESWORTH, S. M.; LEES, J. A. Particulate-associated heavy metals in the urban environment: their transport from the source to deposit, Coventry, UK. Chemosphere, v. 39, n.5, p. 833- 848, 1999.

CHARLESWORTH, S. M.; EVERETT, M.; McARTHY, R.; ORDOÑEZ, A.; MIGUEL, E. A comparative study of heavy metal concentration and distribution in deposited street dusts in a large and a small urban area: Birmingham and Coventry, West Midlands, UK.

Environment International, n. 29, p. 563 -573, 2003.

COHEN, J. Statistical power analysis for the behavioral sciences. Hillsdale, v. 31, p. 489500. Erlbaum,1998.

COUTINHO, L.M.C. Aspectos do solo do cerrado. Disponível em: <http://ecologia.ib.usp.br/cerrado/aspectos solo.htm>. Acesso em: fev. 2015.

DANCEY,C; REIDY,J. Estatística sem matemática para psicologia: usando SPSS para Windows. Porto Alegre: Bookman, 2006.

DIAS, J.W.C. Manual de operação: Amostrador de Grande Volume para Partículas Totais em Suspensão - Avg Pts. Energética, Rio de Janeiro. 2012. 
DOTTO,C. Acumulação e balanço de sedimentos em superfícies asfálticas em área urbana de Santa Maria - RS. Santa Maria, RS: UFSM. Dissertação de mestrado.

Universidade Federal de Santa Maria, 2006.

DUZGOREN-AYDIN, N. S.; WONG, C. S.; AYDIN, A.; SONG, Z.; YOU, M.; LI, X. D. Heavy metal contamination and distribution in the urban environment of Guangzhou, SE China.

Environmental Geochemistry and Health, n. 38, p. 375-391, 2006.

EGODAWATTA, P.; THOMAS, E.; GOONETILLEKE, A. Mathematical interpretation of pollutant wash-off from urban road surfaces using simulated rainfall. Water Research, v. 41, p. 3025-3031, 2007.

HERNGREN, L; GOONETILLEKE, A.; AYOKO, G.A. Analysis of heavy metals in roaddeposited sediments. Analytica Chimical Acta, v. 571, p. 270-278, 2006.

IBGE - INSTITUTO BRASILEIRO DE GEOGRAFIA E ESTATÍSTICAS. Cidades: Goiânia. Disponível em:

$<$ http://www.cidades.ibge.gov.br/xtras/uf.php?lang=\&coduf=52\&search=goias $>$. Acesso em: abril, 2014.

INMET - INSTITUTO NACIONAL DE METEOROLOGIA. Estações e dados: dados meteorológicos. Disponível em:

$<$ http://www.inmet.gov.br/portal/index.php?r=estacoes/estacoesAutomaticas >. Acesso em: jun. 2014.

LUIZ, G.C.; MESQUITA, M.E.A. Ensaio ao entendimento da poluição do ar em Goiânia Go. Anais do VI Simpósio Brasileiro de Climatologia Geográfica, UFS, Aracaju, 2004. Disponível em:

<http://www.observatoriogeogoias.iesa.ufg.br/uploads/215/original MESQUITA Maria ente ndimento polui o.pdf> . Acesso em: mar. 2014.

MARTíNEZ, L.L.G. Distribuição de poluição difusa por sedimentos urbanos em áreas impermeáveis em Porto Alegre. Dissertação apresentada ao Programa de Pós-Graduação em Recursos Hídricos e Saneamento Ambiental da Universidade Federal do Rio Grande do Sul. 2010.

MUDROCH, A.; AZCUE, J.M. Manual of aquatic sediment sampling. Florida, EUA: CRC press, 1995. 219p.

NICODEMOS, R. M.; JESUS, A. R.; FOUTOURA, R.S.; LIRA, T.S.; LIMA, E.A.P.; ASSIS A.J.; BARROSO, M.A.S. Análise da qualidade do ar atmosférico na cidade de Uberlândia no ano de 2008. In: IX ENCONTRO INTERNO \& SEMINÁRIO DE INICIAÇÃO CIENTÍFICA, 9, 2008. Anais.... Universidade Federal de Uberlândia - Diretoria de Pesquisa, 2008.

PEREIRA , J.A.; BAPTISTA - NETO, J.; SMITH, B.J.; McALLISTER, J.J. The contribution of heavy metal pollution derived from highway runoff to Guanabara Bay sediments - Rio de Janeiro / Brazil. Anais da Academia Brasileira das Ciências, Rio de Janeiro, v. 79, n. 4, p. $739-750,2007$

POLETO, C.; BORTOLUZZI, E.C.; CHARLESWORTH, S.; MERTEN, G.H. Urban Sediment Particle Size and Pollutants in Southern Brazil. Journal of Soils and Sediments, n. 9, p. 317- 327, 2009.

POLETO, C.; CASTILHO, Z.C. Impacto por poluição difusa de sedimentos em bacias urbanas. In: POLETO, C. (Org.) Ambiente e sedimentos. Porto Alegre: Ed. ABRH, 2008. p. 193-227, 
POLETO, C.; MARTÍNEZ, L.L.G. Sedimentos urbanos: ambiente e água. Holos Environment, v.11, n.1, p. 2, 2011.

SECRETARIA MUNICIPAL DE DESENVOLVIMENTO URBANO SUSTENTAVEL SEMDUS. Goiânia em dados - anuário estatístico. 2010. Disponível em:

$<$ http://www.goiania.go.gov.br/shtml/seplam/anuario2012/anuario.html >. Acesso em: abr. 2014.

SILVA, E. P. Acúmulo e carreamento de metais pesados e sólidos em superfícies asfálticas. Dissertação de mestrado apresentada ao Programa de Pós-Graduação em Engenharia do Meio Ambiente da Universidade Federal de Goiás. Goiânia, 2013.

SILVA, E. P.; SIQUEIRA, E.Q.; SCHIMIDT, F.; GUEDES, C. S. Determinação de metais pesados em sedimentos urbanos por fluorescência de raios-x. Holos Environment, v. 14, n. 1, p. 87. 2014.

SILVA, E. P.; SIQUEIRA, E.Q.; LEANDRO, W.M. Metais tóxicos em sedimentos urbanos de superfícies asfálticas. Revista Brasileira de Recursos Hídricos, RBRH, v. 20, n.1, p. 226236, Porto Alegre. 2015.

SUTHERLAND, R. Lead in grain size fractions of road-deposited sediment. Environmental Pollution, n. 121, p. $229-237,2003$.

VAZE, J., CHIEW, F. H. S. Experimental study of pollutant accumulation on an urban road surface. Urban Water, p. 379-389. 2002. 